\title{
EVALUASI JALUR EVAKUASI KEBAKARAN PADA KANTOR BUPATI NAGAN RAYA
}

\author{
Nurfajrida $^{1)}$, Mochammad Afifuddin ${ }^{2)}$, Abdullah $^{3)}$ \\ ${ }^{1)}$ Magister Teknik Sipil, Fakultas Teknik, Universitas Syiah Kuala, Banda Aceh \\ ${ }^{2), 3)}$ Jurusan Teknik Sipil, Fakultas Teknik, Universitas Syiah Kuala, Banda Aceh \\ email: nurfajridaririn@gmail.com
}

DOI: http://dx.doi.org/10.29103/tj.v9i2.207

(Received: May 2019 / Revised: May 2019 / Accepted: June 2019)

\begin{abstract}
Abstrak
Kebakaran adalah suatu kejadian yang tidak diinginkan dan kadang kala tidak dapat dikendalikan, sebagai hasil pembakaran suatu bahan dalam udara dan mengeluarkan energi panas serta nyala (api). Kebakaran dapat terjadi di mana saja baik di hutan, pemukiman maupun di gedung perkantoran. Pengguna bangunan gedung harus mampu keluar secepat mungkin dengan menghindari rintangan yang terjadi, dan harus memilih pintu keluar yang tepat agar tidak terluka dan menjadi korban dari peristiwa kebakaran tersebut. Proses penyelamatan ini disebut dengan evakuasi. Berdasarkan pengamatan awal kondisi bangunan publik Kantor Bupati Kabupaten Nagan Raya belum sepenuhnya memenuhi persyaratan jalur evakuasi terhadap Peraturan Menteri Pekerjaan Umum dan Perumahan Rakyat Republik Indonesia Nomor 14/PRT/M/2017. Penelitian ini bertujuan untuk mengevaluasi jalur evakuasi dan merumuskan strategi pengurangan risiko bencana kebakaran di Kantor Bupati Kabupaten Nagan Raya. Penelitian ini menggunakan metode kualitatif dan kuantitatif. Evaluasi jalur evakuasi kebakaran pada gedung menggunakan Permen PUPR RI No. 14/PRT/M/2017, yang meliputi 3 bagian utama yaitu akses eksit, eksit, dan eksit pelepasan. Analisis strategi menggunakan analisi Strengths Weaknesses Opportunities Threats (SWOT). Hasil penelitian menunjukkan bahwa jalur evakuasi di Kantor Bupati Kabupaten Nagan Raya untuk gedung A sebagian besar terpenuhi syarat yaitu sebanyak 16 persyaratan (53\%), gedung $\mathrm{B}$ dan gedung $\mathrm{C}$ hampir sebagian besar terpenuhi syarat yaitu samasama sebanyak 15 persyaratan $(56 \%)$. Strategi pengurangan risiko bencana kebakaran di Kantor Bupati Kabupaten Nagan Raya adalah melakukan kegiatan pengembangan melalui sistem proteksi aktif dan proteksi pasif, mengevaluasi tingkat kedisiplinan pegawai terhadap peraturan larangan merokok dalam gedung, dan memberikan pendidikan dan pelatihan kepada pegawai terkait upaya pengurangan risiko bencana.
\end{abstract}

Kata kunci: Jalur evakuasi, bangunan publik, risiko, bencana, kebakaran

\begin{abstract}
Fire is an unwanted event and sometimes cannot be controlled, as a result of burning a material in the air and releasing heat energy and flame. Fires can occur anywhere in the forest, settlements or office buildings. Users of buildings must be able to get out as quickly as possible by avoiding obstacles that occur, and must choose the right exit so as not to get hurt and become a victim of the fire incident. This rescue process is called evacuation. Based on preliminary observations on the condition of public buildings, the Nagan Raya District Head Office has not yet fully fulfilled the requirements for the evacuation route to the Minister of Public Works and Public Housing Regulation of the Republic of Indonesia Number 14/PRT/M/2017. This study aims to evaluate the evacuation route and formulate a strategy for reducing the risk of fire disaster at the Regent Office of Nagan Raya District. This study uses qualitative
\end{abstract}


and quantitative methods. Evaluation of fire evacuation routes in the building using Republic of Indonesia PUPR Regulation Number 14/PRT/M/2017, which includes 3 main parts namely exit access, excitation, and release excitation. Analysis of strategies is using analysis of Strengths Weaknesses Opportunities Threats (SWOT). The results showed that most of the evacuation routes at the Nagan Raya District Head Office for building A were fulfilled, namely as many as 16 requirements (53\%), building B and building $C$ almost fulfilled the requirements, namely 15 requirements $(56 \%)$. The strategy for fire disaster risk reduction at the Nagan Raya District Head Office is to carry out development activities through active protection systems and passive protection, evaluate the level of discipline of employees against smoking ban regulations in buildings, and provide education and training to employees regarding disaster risk reduction efforts.

Keywords: Evacuation routes, public buildings, risks, disasters, fires

\section{Latar Belakang}

Bangunan publik adalah bangunan yang difungsikan sebagai pusat pelayanan masyarakat. Bangunan publik Kantor Bupati adalah bangunan tempat kepala daerah melakukan kegiatan administrasi dan sebagai tempat penyelenggaraan pusat pemerintahan. Kantor Bupati Kabupaten Nagan Raya dalam menyelenggarakan pusat pemerintahan berlokasi di jalan Poros Utama, Desa Lueng Baro, Kecamatan Suka Makmue. Bangunan publik Kantor Bupati dan setiap bangunan lainnya haruslah memenuhi keandalan bangunan, agar dapat memberikan perlindungan bagi pengguna bangunan. Keandalan bangunan adalah kondisi bangunan yang dapat memenuhi persyaratan keselamatan, kesehatan, kenyamanan dan kemudahan. Menurut Undang-undang Republik Indonesia Nomor 28 Tahun 2002 Tentang Bangunan Gedung Pasal 17, disebutkan bahwa persyaratan keselamatan bangunan gedung meliputi persyaratan kemampuan bangunan gedung untuk mendukung beban muatan, serta kemampuan bangunan gedung dalam mencegah dan menanggulangi bahaya kebakaran dan bahaya petir.

Kebakaran adalah suatu kejadian yang tidak diinginkan dan kadang kala tidak dapat dikendalikan, sebagai hasil pembakaran suatu bahan dalam udara dan mengeluarkan energi panas serta nyala api. Kebakaran dapat terjadi di mana saja baik di hutan, pemukiman maupun di gedung perkantoran. Pada saat terjadi kebakaran di bangunan gedung perkantoran, banyak pegawai dan pengunjung secara simultan berlari menuju pintu keluar, saling berdesakan dan mendorong untuk menyelamatkan diri dan harus mampu keluar dari gedung secepat mungkin dengan menghindari rintangan yang terjadi, dan harus memilih pintu keluar yang tepat agar tidak terluka dan menjadi korban dari peristiwa kebakaran tersebut. Proses penyelamatan ini disebut dengan evakuasi. Evakuasi secara sederhana disebut dengan pergerakan manusia dari suatu tempat yang terancam oleh suatu bencana ke tempat yang lebih aman (Hendrik, 2010).

Berdasarkan pengamatan awal kondisi bangunan publik Kantor Bupati Kabupaten Nagan Raya belum sepenuhnya memenuhi persyaratan jalur evakuasi terhadap Peraturan Menteri Pekerjaan Umum dan Perumahan Rakyat Republik Indonesia Nomor 14/PRT/M/2017. Jalur evakuasi yang baik dapat menggerakkan manusia dalam jumlah besar dengan waktu terbatas, sedangkan bila jalur evakuasi tidak tersedia dengan baik, maka dapat menghambat waktu evakuasi serta juga dapat menyebabkan kehilangan nyawa bagi pengguna bangunan. 
Penelitian ini bertujuan untuk mengevaluasi jalur evakuasi dan merumuskan strategi pengurangan risiko bencana kebakaran di Kantor Bupati Kabupaten Nagan Raya.

\section{Metode Penelitian}

\subsection{Evaluasi Jalur Evakuasi}

Evaluasi jalur evakuasi pada bangunan gedung Kantor Bupati Kabupaten Nagan Raya meliputi 3 bagian utama yaitu akses eksit, eksit, dan eksit pelepasan. Jalur evakuasi dievaluasi berdasarkan persyaratan teknis yang terdapat di dalam Permen PUPR RI No. 14/PRT/M/2017. Langkah-langkah evaluasi jalur evakuasi dapat diuraikan sebagai berikut:

1. Setiap bagian akses eksit, eksit, dan eksit pelepasan mempunyai beberapa persyaratan teknis, kompilasi persyaratan teknik tersebut

2. Persyaratan teknis yang terpenuhi syarat diberikan checklist $(\sqrt{ })$, sedangkan yang tidak terpenuhi syarat diberikan strip (-) pada masing-masing gedung.

3. Menghitung total persyaratan teknis yang terpenuhi, dan yang tidak terpenuhi pada masing-masing gedung.

4. Menghitung persentase kesesuaian persyaratan teknis terhadap peraturan, dengan cara total persyaratan teknis yang terpenuhi dibagi dengan total seluruh persyaratan teknis pada masing-masing gedung.

5. Melakukan interprestasi terhadap hasil persentase yang diperoleh berdasarkan Tabel 1.

Tabel 1 Interval penafsiran

\begin{tabular}{lcc}
\hline No. & Interval Nilai & Penafsiran Data \\
\hline 1 & $0 \%$ & Tidak satupun \\
\hline 2 & $1-26 \%$ & Sebagian kecil \\
\hline 3 & $27-49 \%$ & Hampir setengah \\
\hline 4 & $50 \%$ & Setengahnya \\
5 & $51-75 \%$ & Sebagian besar \\
\hline 6 & $76-99 \%$ & Hampir seluruhnya \\
\hline 7 & $100 \%$ & Seluruhnya \\
\hline \multicolumn{3}{c}{ Sumber: Arikunto (2006) } \\
\end{tabular}

\subsection{Analisis Strengths Weaknesses Opportunities Threats (SWOT)}

Analisis SWOT adalah identifikasi berbagai faktor secara sistematis untuk merumuskan strategi perusahaan. Analisis ini didasarkan pada logika yang dapat memaksimalkan kekuatan (strengths) dan peluang (opportunities), namun secara bersamaan dapat meminimalkan kelemahan (weaknesses) dan ancaman (threats) (Rangkuti, 2005). Analisis SWOT dalam penelitian ini digunakan untuk merumuskan strategi pengurangan risiko bencana. Langkah-langkah analisis SWOT ini dapat diuraikan sebagai berikut:

1. Menentukan faktor internal dan faktor eksternal dalam pengurangan risiko bencana melalui observasi dan wawancara. Berdasarkan hasil observasi dan wawancara, maka akan diperoleh indikator-indikator pada aspek kekuatan $(\mathrm{S})$, kelemahan $(\mathrm{W})$, peluang $(\mathrm{O})$, dan ancaman $(\mathrm{T})$.

2. Hasil identifikasi faktor-faktor internal dan eksternal selanjutnya dilakukan penyebaran kuesioner kepada 6 responden (Bupati, Wakil Bupati, Sekda, Asisten Pemerintahan dan Kesejahteraan Rakyat, Asisten Ekonomi dan 
Pembangunan, dan Asisten Administrasi Umum) yang sebelumnya pernah menjadi narasumber. Hal ini berguna agar diperoleh tingkat penilaian indikator yang sangat menentukan pada faktor internal dan eksternal.

3. Membuat rekapitulasi jawaban kuesioner untuk faktor internal dan eksternal.

4. Membuat matriks Internal Factor Evaluation (IFE) dan matriks External Factor Evaluation (EFE). Kedua matriks tersebut mencakup skor, rating, bobot dan skor relatif. Bagian cakupan tersebut diperoleh dari:

a. Nilai skor diperoleh dari penjumlahan skor jawaban dari total responden;

b. Nilai rating diperoleh dari nilai skor dibagi dengan total responden;

c. Nilai bobot diperoleh dari nilai skor indikator dibagi dengan nilai total skor indikator;

d. Nilai skor relatif diperoleh dari nilai rating dikali dengan nilai bobot; dan

e. Nilai total skor diperoleh dari penjumlahan skor relatif dari masing-masing indikator untuk setiap aspek.

f. Nilai selisih matriks IFE diperoleh dari total skor kekuatan (S) dikurang total skor kelemahan (W), dimana nilai selisih matriks IFE ini adalah nilai untuk sumbu x pada diagram kuadran SWOT.

5. Membuat diagram matriks Strategic Position and Action Evaluation (SPACE). Titik $\mathrm{S}$ ke $\mathrm{W}$ dijadikan sebagai garis koordinat $\mathrm{x}$ (sumbu horizontal), dan titik O ke titik T dijadikan sebagai garis koordinat y (sumbu vertikal). Selanjutnya menghubungkan nilai selisih pada matriks IFE, dengan nilai selisih pada matriks EFE pada sumbu koordinat $x$, y. Nilai selisih yang dihubungkan tersebut akan terletak di salah satu kuadran SWOT. Diagram matriks SPACE yang berisikan 4 kuadran. Maksud strategi pada masingmasing kuadran tersebut adalah sebagai berikut:

a. Kuadran I (positif, positif). Kuadran ini menunjukkan bahwa strategi yang harus dilakukan adalah menggunakan kekuatan untuk memanfaatkan peluang (strategi S-O).

b. Kuadran II (positif, negatif). Kuadran ini menunjukkan bahwa strategi yang harus dilakukan adalah menggunakan kekuatan untuk mengatasi ancaman (strategi S-T).

c. Kuadran III (negatif, positif). Kuadran ini menunjukkan bahwa strategi yang harus dilakukan adalah meminimalkan kelemahan dan memanfaatkan peluang (strategi W-O).

d. Kuadran IV (negatif, negatif). Kuadran ini menunjukkan bahwa strategi yang harus dilakukan adalah meminimalkan kelemahan dan menghindari ancaman (strategi W-T).

\section{Hasil dan Pembahasan}

\subsection{Evaluasi Jalur Evakuasi}

Jalur evakuasi adalah jalan keluar menerus dan tidak terhalangi oleh sesuatu yang dapat dilalui pengguna bangunan menuju ke tempat yang aman, apabila terjadi kebakaran pada suatu ruang atau beberapa ruang. Jalur evakuasi pada gedung Kantor Bupati Kabupaten Nagan Raya adalah akses eksit, eksit, dan eksit pelepasan. Pada bangunan tersebut akses eksit berupa jalur gangway, eksit berupa koridor, tangga, dan pintu, sedangkan eksit pelepasan berupa teras. Keandalan jalur evakuasi ini dapat dilihat dari sejauh mana jalur evakuasi yang ada dapat memenuhi syarat. Jalur evakuasi dievaluasi berdasarkan persyaratan teknis yang 
ditetapkan oleh Permen PUPR RI No. 14/PRT/M/2017. Kondisi eksisting sarana jalur evakuasi pada gedung Kantor Bupati diperlihatkan pada Tabel 2.

Tabel 2 Evaluasi sarana jalur evakuasi gedung kantor bupati

\begin{tabular}{|c|c|c|c|c|c|}
\hline \multirow{2}{*}{ No. } & \multirow{2}{*}{\multicolumn{2}{|c|}{ Persyaratan Teknis Sarana Jalur Evakuasi }} & \multicolumn{3}{|c|}{$\begin{array}{l}\text { Observasi } \\
\text { Gedung }\end{array}$} \\
\hline & & & $\mathbf{A}$ & $\mathbf{B}$ & $\mathbf{C}$ \\
\hline \multirow[t]{11}{*}{1} & \multicolumn{5}{|c|}{ Akses eksit } \\
\hline & $\mathrm{a}$ & Akses eksit harus terproteksi dari bahaya kebakaran & - & $\sqrt{ }$ & $\sqrt{ }$ \\
\hline & $\mathrm{b}$ & $\begin{array}{l}\text { Akses eksit harus bebas dari segala hambatan/halangan seperti } \\
\text { pagar penghalang, gerbang, furnitur, dekorasi, atau benda yang } \\
\text { menghalangi pintu keluar, akses ke dalamnya, jalan keluar } \\
\text { darinya, atau visibilitas daripadanya }\end{array}$ & $\sqrt{ }$ & $\sqrt{ }$ & $\sqrt{ }$ \\
\hline & $\mathrm{c}$ & $\begin{array}{l}\text { Akses eksit harus diberi penanda yang mudah terlihat agar } \\
\text { mudah ditemukan dan dikenali }\end{array}$ & - & - & - \\
\hline & $\mathrm{d}$ & $\begin{array}{l}\text { Akses eksit } 1 \text { arah menuju ke } 1 \text { eksit, lebar minimal akses eksit } \\
\text { harus paling sedikit bisa dilalui oleh kursi roda }(92 \mathrm{~cm})\end{array}$ & $\sqrt{ }$ & $\sqrt{ }$ & $\sqrt{ }$ \\
\hline & e & $\begin{array}{l}\text { Akses eksit lebih dari } 2 \text { arah menuju ke } 1 \text { eksit, masing-masing } \\
\text { akses eksit harus memiliki lebar yang cukup untuk jumlah } \\
\text { orang yang dilayaninya }\end{array}$ & $\sqrt{ }$ & $\sqrt{ }$ & $\sqrt{ }$ \\
\hline & $\mathrm{f}$ & $\begin{array}{l}\text { Lebar akses eksit diukur dari titik tersempit dalam hal akses } \\
\text { eksit memiliki lebar yang tidak seragam }\end{array}$ & $\sqrt{ }$ & $\sqrt{ }$ & $\sqrt{ }$ \\
\hline & $\mathrm{g}$ & $\begin{array}{l}\text { Akses eksit di luar ruangan dapat melalui balkon, serambi atau } \\
\text { atap }\end{array}$ & $\sqrt{ }$ & $\sqrt{ }$ & $\sqrt{ }$ \\
\hline & $\mathrm{h}$ & $\begin{array}{l}\text { Akses eksit di luar ruangan harus dilengkapi dengan kantilever, } \\
\text { dinding pengaman dan menggunakan material penutup lantai } \\
\text { yang lembut dan solid }\end{array}$ & $\sqrt{ }$ & $\sqrt{ }$ & $\sqrt{ }$ \\
\hline & i & $\begin{array}{l}\text { Pintu akses eksit dapat dipasang di sepanjang jalur } \\
\text { penyelamatan menuju eksit atau sebagai akses ke ruangan atau } \\
\text { ruang selain toilet, kamar tidur, gudang, ruang utilitas, pantri } \\
\text { dan sejenisnya }\end{array}$ & $\sqrt{ }$ & $\sqrt{ }$ & $\sqrt{ }$ \\
\hline & $\mathrm{j}$ & Pintu akses eksit harus secara jelas mudah dikenali & - & - & - \\
\hline \multicolumn{6}{|c|}{$2 \quad$ Eksit } \\
\hline & a & $\begin{array}{l}\text { Bangunan gedung dengan ketinggian sedang dan tinggi serta } \\
\text { bangunan gedung umum di atas } 1 \text { lantai harus dilengkapi } \\
\text { dengan eksit berupa tangga eksit yang tertutup dan terlindung } \\
\text { dari api, asap kebakaran, dan rintangan lainnya }\end{array}$ & - & - & - \\
\hline & $\mathrm{b}$ & $\begin{array}{l}\text { Lebar tangga eksit dan bordes untuk kapasitas sampai dengan } \\
50 \text { orang paling sedikit } 90 \mathrm{~cm}\end{array}$ & $\sqrt{ }$ & $\sqrt{ }$ & $\sqrt{ }$ \\
\hline & $\mathrm{c}$ & $\begin{array}{l}\text { Tangga eksit harus dilengkapi dengan pegangan rambat } \\
\text { (handrail) setinggi } 110 \mathrm{~cm} \text { dan mempunyai lebar anak } \\
\text { tangga paling sedikit } 30 \mathrm{~cm} \text { dengan ketinggian paling besar } \\
18 \mathrm{~cm}\end{array}$ & - & - & - \\
\hline & & $\begin{array}{l}\text { Bangunan gedung dengan ketinggian sampai dengan } 3 \text { lantai, } \\
\text { eksit harus terlindungi dengan Tingkat Ketahanan Api } \\
\text { (TKA) paling sedikit } 1 \text { jam }\end{array}$ & $\sqrt{ }$ & & \\
\hline & $\mathrm{e}$ & $\begin{array}{l}\text { Jika terdapat lebih dari } 1 \text { eksit pada } 1 \text { lantai, sedikitnya harus } \\
\text { tersedia } 2 \text { eksit yang terpisah untuk meminimalkan } \\
\text { kemungkinan keduanya terhalang oleh api atau keadaan } \\
\text { darurat lainnya }\end{array}$ & $\sqrt{ }$ & $\sqrt{ }$ & $\sqrt{ }$ \\
\hline & $\mathrm{f}$ & $\begin{array}{l}\text { Pintu eksit harus diberi penanda yang mudah terlihat agar } \\
\text { mudah dikenali }\end{array}$ & - & - & - \\
\hline & & $\begin{array}{l}\text { Penanda eksit harus memiliki warna khusus dan kontras } \\
\text { dengan dekorasi, penyelesaian interior, dan penanda lainnya }\end{array}$ & - & - & - \\
\hline
\end{tabular}




\begin{tabular}{|c|c|c|c|c|c|}
\hline & $\mathrm{h}$ & $\begin{array}{l}\text { Penanda eksit harus mengandung kata "EKSIT" yang mudah } \\
\text { dibaca dengan tinggi huruf paling kurang } 15 \mathrm{~cm} \text { dan lebar } \\
\text { huruf paling kurang } 1,875 \mathrm{~cm}\end{array}$ & - & - & - \\
\hline & $\mathrm{i}$ & $\begin{array}{l}\text { Penanda eksit bertuliskan "EKSIT" atau penanda sejenis } \\
\text { dengan anak panah yang menunjukkan arah eksit, harus } \\
\text { ditempatkan pada akses eksit untuk mengarahkan pada eksit } \\
\text { terdekat }\end{array}$ & - & - & - \\
\hline & $\mathrm{j}$ & $\begin{array}{l}\text { Pintu eksit harus menggunakan jenis pintu ayun (swinging } \\
\text { door) yang dapat menutup otomatis }\end{array}$ & - & - & - \\
\hline & $\mathrm{k}$ & $\begin{array}{l}\text { Pintu eksit yang membuka ke arah lorong atau jalan terusan } \\
\text { yang berfungsi sebagai akses eksit tidak boleh membatasi } \\
\text { lebar efektif akses eksit tersebut }\end{array}$ & $\sqrt{ }$ & $\sqrt{ }$ & $\sqrt{ }$ \\
\hline & 1 & $\begin{array}{l}\text { Pintu eksit tidak dibolehkan dilengkapi/berhadapan dengan } \\
\text { cermin atau ditutup dengan tirai/gorden }\end{array}$ & $\sqrt{ }$ & $\sqrt{ }$ & $\sqrt{ }$ \\
\hline & $\mathrm{m}$ & $\begin{array}{l}\text { Untuk eksit yang melayani lebih dari } 1 \text { lantai, pengguna } \\
\text { bangunan gedung dan pengunjung bangunan gedung di } \\
\text { setiap lantai dipertimbangkan secara individual untuk } \\
\text { menghitung kapasitas eksit di setiap lantai tersebut sehingga } \\
\text { kapasitas eksit tidak akan berkurang sepanjang arah } \\
\text { perjalanan keluar }\end{array}$ & $\sqrt{ }$ & $\sqrt{ }$ & $\sqrt{ }$ \\
\hline & $\mathrm{n}$ & $\begin{array}{l}\text { Jika terdapat pintu, bagian, atau tangga yang bukan sebagai } \\
\text { eksit dan dapat disalahtafsirkan sebagai sebuah eksit, perlu } \\
\text { diberikan identifikasi dengan penanda "bukan jalan keluar" } \\
\text { atau sesuai dengan fungsi ruang sebenarnya }\end{array}$ & - & & \\
\hline & o & $\begin{array}{l}\text { Beberapa perangkat deteksi seperti alarm dapat dipasang } \\
\text { untuk membatasi penyalahgunaan eksit yang dapat } \\
\text { mengakibatkan kegagalan fungsi eksit, menghambat atau } \\
\text { menghalangi proses evakuasi Pengguna Bangunan Gedung } \\
\text { dan Pengunjung Bangunan Gedung. }\end{array}$ & - & & \\
\hline & $\mathrm{p}$ & $\begin{array}{l}\text { Eksit harus memiliki ruang yang cukup untuk menempatkan } \\
\text { kursi roda saat terjadi kebakaran atau keadaan darurat } \\
\text { lainnya }\end{array}$ & $\sqrt{ }$ & $\sqrt{ }$ & $\sqrt{ }$ \\
\hline & $\mathrm{q}$ & Jumlah paling sedikit tangga eksit 2 buah & $\sqrt{ }$ & - & - \\
\hline 3 & \multicolumn{5}{|c|}{ Eksit pelepasan } \\
\hline & $\mathrm{a}$ & $\begin{array}{l}\text { Eksit pelepasan harus berada di permukaan tanah atau } \\
\text { langsung ke ruang terbuka yang aman di luar bangunan } \\
\text { gedung }\end{array}$ & $\sqrt{ }$ & $\sqrt{ }$ & $\sqrt{ }$ \\
\hline & $\mathrm{b}$ & $\begin{array}{l}\text { Ruang terbuka yang aman di luar bangunan gedung dapat } \\
\text { berupa selasar terbuka yang tidak digunakan untuk kegiatan } \\
\text { komersial dengan lebar tidak lebih dari } 5 \mathrm{~m} \text { diukur dari } \\
\text { dinding bagian luar bangunan gedung }\end{array}$ & - & - & - \\
\hline & $\mathrm{c}$ & $\begin{array}{l}\text { Pada bangunan hunian yang tidak dilengkapi dengan sistem } \\
\text { sprinkler otomatis, paling sedikit } 50 \% \text { dari jumlah total } \\
\text { tangga eksit harus dilepaskan ke ruang terbuka yang aman di } \\
\text { luar bangunan gedung dan untuk tangga eksit yang tersisa } \\
\text { diperbolehkan untuk dilepaskan ke ruang sirkulasi tertutup di } \\
\text { permukaan tanah }\end{array}$ & - & - & - \\
\hline \multicolumn{3}{|r|}{ Jumlah persyaratan teknis } & 30 & 27 & 27 \\
\hline \multicolumn{3}{|c|}{ Jumlah persyaratan teknis terpenuhi } & 16 & 15 & 15 \\
\hline \multicolumn{3}{|c|}{ Persentase terpenuhi syarat } & $53 \%$ & $56 \%$ & $56 \%$ \\
\hline \multicolumn{3}{|c|}{ Jumlah persyaratan teknis tidak terpenuhi syarat } & 14 & 12 & 12 \\
\hline \multicolumn{3}{|c|}{ Persentase tidak terpenuhi syarat } & $47 \%$ & $44 \%$ & $44 \%$ \\
\hline
\end{tabular}


Dari Tabel 2 diperlihatkan bahwa gedung A dari 30 persyaratan yang dievaluasi, sebagian besar terpenuhi syarat yaitu sebanyak 16 persyaratan (53\%), dan hampir setengah tidak terpenuhi syarat yaitu sebanyak 14 persyaratan (47\%). Gedung B dan gedung $\mathrm{C}$ dari 27 persyaratan yang dievaluasi, secara simultan sebagian besar terpenuhi syarat yaitu sebanyak 15 persyaratan $(56 \%)$, dan hampir setengah tidak terpenuhi syarat yaitu sebanyak 12 persyaratan (44\%). Adapun perbedaan jumlah persyaratan teknis antara gedung A terhadap gedung $\mathrm{B}$ dan $\mathrm{C}$ dikarenakan tiga hal, pertama pada gedung A mempunyai ketinggian 3 lantai sehingga Tingkat Ketahanan Api (TKA) paling sedikit 1 jam, sedangkan pada gedung $\mathrm{B}$ dan $\mathrm{C}$ mempunyai ketinggian 2 lantai sehingga TKA tidak dipersyaratkan, kedua pada gedung A terdapat pintu yang bukan sebagai eksit, sedangkan pada gedung $\mathrm{B}$ dan $\mathrm{C}$ tidak mempunyai pintu yang bukan sebagai eksit, ketiga pada gedung A seharusnya beberapa perangkat deteksi seperti alarm dapat dipasang untuk membatasi penyalahgunaan eksit karena terdapat pintu yang bukan sebagai eksit, sedangkan pada gedung B dan C beberapa perangkat deteksi seperti alarm memang tidak perlu dipasang untuk membatasi penyalahgunaan eksit karena tidak terdapat pintu yang bukan sebagai eksit.

Sejalan dengan penelitian terdahulu yang dilakukan oleh Sari dan Hardi (2015) diperoleh hasil bahwa jalur evakuasi pada Wisma Barito Pasific telah memenuhi standar diantaranya pada aspek dimensi lebar dan tinggi koridor, jarak ke tangga darurat $15 \mathrm{~m}$, tempat dua jalan keluar. Jalur evakuasi tersebut dievaluasi berdasarkan Keputusan Menteri Nomor 10/KPTS/2000. Jalur evekuasi yang dievaluasi mulai dari akses eksit, pintu kebakaran, petunjuk arah, tempat berkumpul, tangga kebakaran, dan penerangan darurat. Persepsi dari karyawan Wisma Barito Pasific menyatakan bahwa jalur evakuasi atau koridor aman untuk dilalui saat evakuasi bencana.

Demikian juga dengan penelitian terdahulu yang dilakukan oleh Putra (2014) diperoleh hasil bahwa tingkat keandalan sarana penyelamatan jiwa terhadap bahaya kebakaran pada bangunan gedung Perpustakaan Universitas Andalas untuk tangga kebakaran sebesar $66,67 \%$, akses jalan keluar sebesar $52,38 \%$, dan pintu kebakaran sebesar 57,14\%. Tingkat keandalan sarana penyelamatan jiwa terhadap bahaya kebakaran pada bangunan gedung Rektorat Universitas Andalas untuk tangga kebakaran sebesar 45,45\%, akses jalan keluar sebesar $61,90 \%$, dan pintu kebakaran sebesar 90,48\%. Secara keseluruhan tingkat keandalan sarana penyelamatan jiwa terhadap bahaya kebakaran pada bangunan gedung Pepustakaan Universitas Andalas adalah sebesar 58.73\% dan pada bangunan gedung Rektorat Universitas Andalas adalah sebesar 65.94 \%. Sarana penyelamatan jiwa tersebut dievaluasi menggunakan beberapa peraturan yaitu Peraturan Menteri Pekerjaan Umum Nomor 26/PRT/M/2008, SNI 03-1746-2000, SNI 03-1736-2000 dan SNI 03-6574-2001.

\subsection{Pengurangan Risiko Bencana Kebakaran}

Pengurangan risiko bencana kebakaran di Kantor Bupati Kabupaten Nagan Raya, dibutuhkan analisis yang mampu mempertemukan aspek-aspek kekuatan, kelemahan, peluang dan aspek ancaman. Oleh karena itu untuk menganalisis strategi pengurangan risiko bencana kebakaran di Kantor Bupati, maka digunakan analisis SWOT. Faktor internal dan eksternal dari hasil wawancara tersebut, telah dilakukan penilaian tingkat indikator yang sangat menentukan, melalui 
penyebaran kuesioner kepada responden yang pernah menjadi narasumber. Berdasarkan penilaian responden untuk faktor internal dan faktor eksternal, maka berikut ini dilakukan perhitungan matriks IFE dan matriks EFE seperti diperlihatkan pada Tabel 3 dan Tabel 4.

Tabel 3 Perhitungan matriks IFE

\begin{tabular}{|c|c|c|c|c|c|}
\hline No. & Kekuatan (Strengths) & $\begin{array}{c}\text { Jumlah } \\
\text { Skor }\end{array}$ & Rating & $\begin{array}{c}\text { Bobot } \\
(\%)\end{array}$ & $\begin{array}{c}\text { Skor } \\
\text { Bobot }\end{array}$ \\
\hline 1 & $\begin{array}{l}\text { Jumlah akses gedung } \mathrm{A}, \mathrm{B} \text { dan } \mathrm{C} \text { sedikitnya } \\
\text { terdapat } 2 \text { jalan keluar }\end{array}$ & 30 & 5 & 0,10 & 0,52 \\
\hline 2 & $\begin{array}{l}\text { Jalur keluar gedung } \mathrm{B} \text { dan } \mathrm{C} \text { terlindungi dari } \\
\text { bahaya kebakaran }\end{array}$ & 28 & 4,7 & 0,10 & 0,46 \\
\hline 3 & $\begin{array}{l}\text { Setiap jalur keluar gedung } \mathrm{A}, \mathrm{B} \text { dan } \mathrm{C} \text { tidak } \\
\text { terhalangi oleh sesuatu yang dapat menghambat } \\
\text { proses evakuasi }\end{array}$ & 30 & 5 & 0,10 & 0,52 \\
\hline 4 & $\begin{array}{l}\text { Jalur keluar gedung A, B dan } \mathrm{C} \text { mempunyai } \\
\text { tinggi bebas }>2 \mathrm{~m} \text { dan lebar }>1 \mathrm{~m}\end{array}$ & 28 & 4,7 & 0,10 & 0,46 \\
\hline 5 & $\begin{array}{l}\text { A, B dan C langsung menuju } \\
\text { uka }\end{array}$ & 30 & 5 & 0,10 & 0,52 \\
\hline 6 & $\begin{array}{l}\text { Jarak tempuh keluar ke tempat aman pada gedung } \\
\mathrm{B} \text { dan } \mathrm{C} \text { tanpa sprinkler tidak melebihi batas } \\
\text { maksimal } 70 \mathrm{~m}\end{array}$ & 28 & 4,7 & 0,10 & 0,46 \\
\hline 7 & $\begin{array}{l}\text { Gedung A terdapat Alat Pemadam Api Ringan } \\
\text { (APAR) pada setiap lantainya }\end{array}$ & 27 & 4,5 & 0,09 & 0,42 \\
\hline 8 & Terdapat pemisahan blok-blok bangunan gedung & 30 & 5 & 0,10 & 0,52 \\
\hline 9 & $\begin{array}{l}\text { Pengguna bangunan (pegawai dan pengunjung) } \\
\text { sudah mempunyai pengetahuan yang baik } \\
\text { terhadap jalur evakuasi }\end{array}$ & 27 & 4,5 & 0,09 & 0,42 \\
\hline 10 & madam kebakaran & 29 & 4,8 & 0,10 & 0,49 \\
\hline & & 287 & & 1 & 4,79 \\
\hline No. & Kelemahan (Weakness) & $\begin{array}{l}\text { Jumlah } \\
\text { Skor }\end{array}$ & & $\begin{array}{c}\text { Bobot } \\
(\%)\end{array}$ & $\begin{array}{c}\text { Skor } \\
\text { Bobot }\end{array}$ \\
\hline 1 & $\begin{array}{l}\text { Jalur keluar gedung A tidak terlindungi dari } \\
\text { bahaya kebakaran }\end{array}$ & 27 & 4,5 & 0,06 & 0,26 \\
\hline 2 & $\begin{array}{l}\text { uh keluar ke tempat aman pada gedung } \\
\text { inkler melebihi batas maksimal } 70 \mathrm{~m}\end{array}$ & 29 & 4,8 & 0,06 & 0,30 \\
\hline 3 & $\begin{array}{l}\text { edia sumber daya listrik darurat pada } \\
\text { B dan C }\end{array}$ & 27 & 4,5 & 0,06 & 0,26 \\
\hline 4 & $\begin{array}{l}\text { Tidak tersedia lampu darurat pada gedung A, B } \\
\text { dan C }\end{array}$ & 27 & 4,5 & 0,06 & 0,26 \\
\hline 5 & & 28 & 4,7 & 0,06 & 0,28 \\
\hline 6 & ge Kéanal all paua ge & 28 & 4,7 & 0,06 & 0,28 \\
\hline 7 & $\begin{array}{l}\text { Tidak tersedia pintu dan tangga darurat pada } \\
\text { gedung B dan C }\end{array}$ & 28 & 4,7 & 0,06 & 0,28 \\
\hline 8 & $\begin{array}{l}\text { Tidak tersedia sistem kendali asap pada gedung } \\
\text { A, B dan C }\end{array}$ & 27 & 4,5 & 0,06 & 0,26 \\
\hline 9 & $\begin{array}{l}\text { Tidak tersedia alat komunikasi darurat pada } \\
\text { gedung A, B dan C }\end{array}$ & 30 & 5 & 0,06 & 0,32 \\
\hline 10 & Tidak tersedia bukaan penyelamat pada gedung A & 24 & 4 & 0,05 & 0,20 \\
\hline 11 & $\begin{array}{l}\text { Tidak tersedia petunjuk arah jalan keluar pada } \\
\text { gedung } \mathrm{A}, \mathrm{B} \text { dan } \mathrm{C}\end{array}$ & 30 & 5 & 0,06 & 0,32 \\
\hline
\end{tabular}




\begin{tabular}{|c|c|c|c|c|c|}
\hline 12 & Tidak tersedia hidran pada gedung A, B dan C & 28 & 4,7 & 0,06 & 0,28 \\
\hline 13 & $\begin{array}{l}\text { Tidak tersedia alaram kebakaran pada gedung A, } \\
\text { B dan C }\end{array}$ & 30 & 5 & 0,06 & 0,32 \\
\hline 14 & $\begin{array}{l}\text { Tidak tersedia peta evakuasi pada gedung A, B } \\
\text { dan C }\end{array}$ & 27 & 4,5 & 0,06 & 0,26 \\
\hline 15 & Tidak tersedia APAR pada gedung $\mathrm{B}$ dan $\mathrm{C}$ & 29 & 4,8 & 0,06 & 0,30 \\
\hline 16 & $\begin{array}{l}\text { Belum pernah diadakan simulasi atau latihan } \\
\text { pendek terkait dengan proses evakuasi di Kantor } \\
\text { Bupati }\end{array}$ & 27 & 4,5 & 0,06 & 0,26 \\
\hline \multirow[t]{2}{*}{17} & Minimnya biaya pemeliharaan bangunan gedung & 26 & 4,3 & 0,06 & 0,24 \\
\hline & Total kelemahan $(\mathrm{W})$ & 472 & & 1 & 4,64 \\
\hline
\end{tabular}

Tabel 4 Perhitungan matriks EFE

\begin{tabular}{|c|c|c|c|c|c|}
\hline No. & Peluang (Opportunities) & $\begin{array}{l}\text { Jumlah } \\
\text { Skor }\end{array}$ & ating & $\begin{array}{c}\text { Bobot } \\
(\%)\end{array}$ & $\begin{array}{c}\text { Skor } \\
\text { Bobot }\end{array}$ \\
\hline 1 & $\begin{array}{l}\text { Komitmen Pemerintah Provinsi Aceh terhadap } \\
\text { pengurangan risiko bencana }\end{array}$ & 27 & 4,5 & 0,26 & 1,19 \\
\hline 2 & $\begin{array}{l}\text { Sosialisasi dari Pemerintah Provinsi Aceh } \\
\text { terhadap kegiatan kebencanaan }\end{array}$ & 27 & 4,5 & 0,26 & 1,19 \\
\hline 3 & $\begin{array}{l}\text { Disiplinnya pegawai mentaati aturan untuk tidak } \\
\text { merokok di area kantor bupati }\end{array}$ & 24 & 4 & 0,24 & 0,94 \\
\hline 4 & $\begin{array}{l}\text { Struktur bangunan yang masih memungkinkan } \\
\text { untuk pengembangan dalam pengurangan risiko }\end{array}$ & 24 & 4 & 0,24 & 0,94 \\
\hline & Total peluang $(\mathrm{O})$ & 102 & & 1 & 4,26 \\
\hline No. & Ancaman (Threats) & $\begin{array}{l}\text { Jumlah } \\
\text { Skor }\end{array}$ & Rating & $\begin{array}{c}\text { Bobot } \\
(\%)\end{array}$ & $\begin{array}{l}\text { Skor } \\
\text { Bobot }\end{array}$ \\
\hline 1 & $\begin{array}{l}\text { Belum adanya dukungan dana dari Pemerintah } \\
\text { Provinsi Aceh terhadap penanggulangan bencana } \\
\text { di Kantor Bupati }\end{array}$ & 27 & 4,5 & 0,28 & 1,25 \\
\hline 2 & $\begin{array}{l}\text { Pengunjung yang belum disiplin dalam } \\
\text { berkunjung ke kantor bupati, seperti membuang } \\
\text { puntung rokok sembarangan }\end{array}$ & 24 & 4 & 0,25 & 0,99 \\
\hline 3 & $\begin{array}{l}\text { Sumber daya manusia yang tidak tersedia secara } \\
\text { maksimal }\end{array}$ & 20 & 3,3 & 0,21 & 0,69 \\
\hline 4 & Dana yang masih terbatas & 26 & 4,3 & 0,27 & 1,16 \\
\hline & Total ancaman (T) & 97 & & 1 & 4,09 \\
\hline
\end{tabular}

Tabel 3 memperlihatkan bahwa nilai total skor bobot kekuatan (S) diperoleh sebesar 4,79, sedangkan nilai total skor bobot kelemahan (W) diperoleh sebesar 4,64. Oleh karena itu, nilai selisih pada matriks IFE antara kekuatan dengan kelemahan diperoleh sebesar 0,15. 


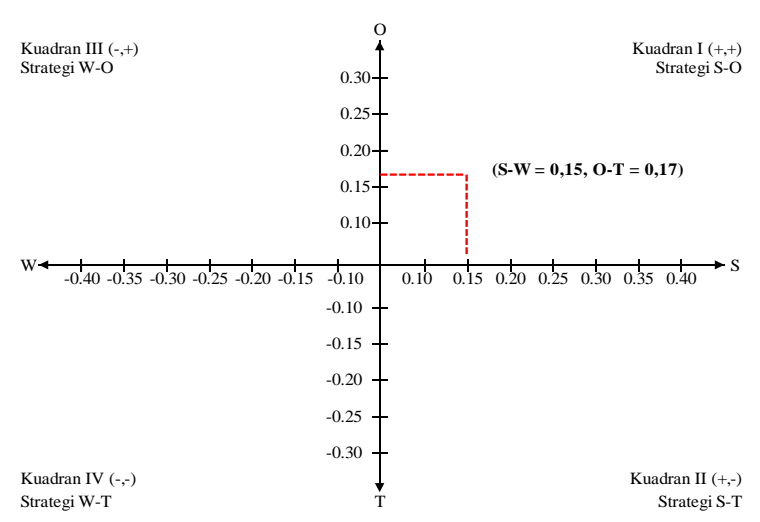

Gambar 1 Kuadran analisis SWOT

Tabel 4 memperlihatkan bahwa nilai total skor bobot peluang $(\mathrm{O})$ diperoleh sebesar 4,26, sedangkan nilai total skor bobot ancaman (T) diperoleh sebesar 4,09. Oleh karena itu, nilai selisih pada matriks EFE antara peluang dengan ancaman diperoleh sebesar 0,17. Berdasarkan nilai selisih pada matriks IFE dan matriks EFE, seperti diperlihatkan kuadran analisis SWOT pada Gambar 1 menunjukkan bahwa nilai selisih matriks IFE dan nilai selisih matriks EFE pada kuadran analisis SWOT dipertemukan pada kuadran I, yang merupakan strategi S-O. Strategi ini dilakukan untuk memanfaatkan seluruh kekuatan dalam memanfaatkan peluang sebesar-besarnya. Rekomendasi strategi S-O dalam pengurangan risiko bencana kebakaran di Kantor Bupati Kabupaten Nagan Raya adalah sebagai berikut:

1. Melakukan kegiatan pengembangan melalui sistem proteksi aktif dan proteksi pasif. Sistem proteksi kebakaran pada bangunan gedung adalah sistem yang terdiri atas peralatan, baik yang terpasang maupun terbangun pada bangunan yang digunakan untuk melindungi bangunan terhadap bahaya kebakaran. Sistem proteksi kebakaran aktif adalah sarana proteksi kebakaran yang harus digerakkan untuk berfungsi dalam memadamkan kebakaran. Kegiatan pengembangan dalam pengurangan risiko bencana kebakaran melalui sistem proteksi aktif adalah seperti pipa tegak, springkler otomatik, pompa pemadam kebakaran, penyediaan air, penambahan Alat Pemadam Api Ringan (APAR), sistem deteksi dan alarm kebakaran, sistem komunikasi, ventilasi mekanik dan pengendalian asap. Sistem proteksi kebakaran pasif adalah sistem proteksi kebakaran yang dibangun, sehingga tidak perlu digerakkan untuk memadamkan kebakaran. Kegiatan pengembangan dalam pengurangan risiko bencana kebakaran melalui sistem proteksi pasif adalah pintu dan jendela tahan api, bahan pelapis interior, kelengkapan perabot, dekorasi dan bahan pelapis yang diberi perlakuan, penghalang api, partisi penghalang asap, dan penghalang asap.

2. Mengevaluasi tingkat kedisiplinan pegawai terhadap peraturan larangan merokok dalam gedung Kantor. Berdasarkan denah layout yang ada, Kantor Bupati tidak memiliki ruang khusus untuk merokok. Hal tersebut, merupakan salah satu penyebab para pegawai merokok di sembarang tempat dalam bangunan gedung. Perilaku merokok di sembarang tempat ini merupakan salah satu faktor penyebab terjadinya kebakaran pada bangunan gedung. Oleh karena itu, mengingat akan bahaya yang timbul para pengambil kebijakan 
telah menetapkan peraturan larangan merokok dalam bangunan gedung. Peraturan tersebut dilakukan baik secara tertulis melalui pemasangan poster maupun secara lisan melalui himbauan apel rutin senin pagi. Berdasarkan pengamatan, tidak sepenuhnya para pegawai mentaati peraturan tersebut. Oleh karena itu, para pegawai yang tidak taat terhadap peraturan larangan merokok dapat diberikan sanksi teguran dan adanya penilaian kedisiplinan.

3. Memberikan pendidikan dan pelatihan kepada pegawai terkait upaya pengurangan risiko bencana. Menanggulangi bencana tidak bisa dilakukan secara mendadak, melainkan butuh persiapan yang harus dilakukan jauh sebelum bencana itu terjadi. Salah satu persiapan yang dapat dilakukan adalah dengan mempersiapkan Sumber Daya Manusia (SDM). Semua pegawai pada Kantor Bupati perlu mengikuti pendidikan dan pelatihan terhadap pengurangan risiko bencana. Pendidikan dan pelatihan ini berguna untuk meningkatkan SDM pegawai tentang pemahaman kesiapsiagaan dalam menghadapi bencana. Kesiapsiagaan adalah upaya yang dilaksanakan oleh pengguna bangunan gedung untuk mengantisipasi kemungkinan terjadinya bencana pada suatu waktu. Kesiapsiagaan merupakan bagian yang tidak terpisahkan dari manajemen bencana secara terpadu.

\section{Kesimpulan dan Saran}

\subsection{Kesimpulan}

Jalur evakuasi di Kantor Bupati Kabupaten Nagan Raya untuk gedung A sebagian besar terpenuhi syarat yaitu sebanyak 16 persyaratan $(53 \%)$, gedung B dan gedung $\mathrm{C}$ hampir sebagian besar terpenuhi syarat yaitu sama-sama sebanyak 15 persyaratan $(56 \%)$. Strategi pengurangan risiko bencana kebakaran adalah melakukan kegiatan pengembangan melalui sistem proteksi aktif dan proteksi pasif, mengevaluasi tingkat kedisiplinan pegawai terhadap peraturan larangan merokok dalam gedung Kantor Bupati, dan melakukan sosialisasi bahaya kebakaran dapat dilakukan dengan pendidikan serta pelatihan kepada pegawai terkait upaya pengurangan risiko bencana.

\subsection{Saran}

Perlu ditingkatkan keandalan jalur evakuasi di gedung Kantor Bupati Nagan Raya sesuai dengan persyaratan, agar pengguna gedung dapat melakukan proses evakuasi dengan selamat dan secepat mungkin bila terjadi kondisi darurat. Perlu diterapkan strategi $\mathrm{S}-\mathrm{O}$ untuk pengurangan risiko bencana kebakaran di Kantor Bupati Nagan Raya, sehingga tingkat keselamatan pengguna bangunan dan bangunan gedung dapat terjaga. pegawai terkait upaya pengurangan risiko bencana.

\section{Daftar Kepustakaan}

Arikunto, S., 2006. Prosedur Penelitian Suatu Pendekatan Praktik. Rineka Cipta, Jakarta.

Hendrik, 2010. Evakuasi dan Penyelamatan Akibat Bencana Kebakaran. Jurnal Manajerial. ISSN: 2085-479X Vol. 2, No. 2. 
Peraturan Menteri Pekerjaan Umum dan Perumahan Rakyat Republik Indonesia, 2017. Nomor 14/PRT/M/2017 Tentang Persyaratan Kemudahan Bangunan Gedung.

Putra, D., 2014. Evaluasi Keandalan Sarana Penyelamatan Jiwa Terhadap Bahaya Kebakaran pada Bangunan Gedung. Jurnal Teknik Sipil, Universitas Andalas, Padang.

Rangkuti, F., 2005. Analisis SWOT: Teknik Membedah Kasus Bisnis. Gramedia, Jakarta.

Sari, N, OP, dan Hardi, J., 2015. Studi Evaluasi Jalur Evakuasi Terhadap Keselamatan Karyawan pada Wisma Barito Pasific. Jurnal Teknik Arsitektur, Universitas Mercu Buana, Jakarta Barat.

Undang-undang Republik Indonesia, 2002. Nomor 28 Tahun 2002 Tentang Bangunan Gedung. 